Research Article

\title{
Proportion and Associated Factors of Low Vision among Adult Patients Attending at University of Gondar Tertiary Eye Care and Training Center, Gondar Town, Ethiopia
}

\author{
Melkamu Temeselew Tegegn (D), Gizachew Tilahun Belete $\mathbb{D}^{D}$, Ayanaw Tsega Ferede, \\ and Aragaw Kegne Assaye \\ University of Gondar, College of Medicine and Health Science, Department of Optometry, P.O. Box 196, Gondar, Ethiopia \\ Correspondence should be addressed to Melkamu Temeselew Tegegn; melkamuopta@gmail.com
}

Received 26 February 2020; Revised 25 April 2020; Accepted 16 May 2020; Published 29 May 2020

Academic Editor: Antonio Longo

Copyright (c) 2020 Melkamu Temeselew Tegegn et al. This is an open access article distributed under the Creative Commons Attribution License, which permits unrestricted use, distribution, and reproduction in any medium, provided the original work is properly cited.

\begin{abstract}
Introduction. Low vision is a worldwide health problem in both developing and developed countries. A national survey of low vision and blindness in Ethiopia showed that the prevalence of low vision was 3.7\% and that of blindness was $1.6 \%$, whereas there is no evidence in the study area. Purpose. The study was aimed to assess the proportion and associated factors of low vision at the University of Gondar tertiary eye care and training center. Methods. A hospital-based cross-sectional study was conducted on 727 study participants with a systematic random sampling technique from April 18 to May 16, 2019. Data were collected through the use of a structural questionnaire and physical eye examination. Data were entered into Epi Info version 7 , and analysis was performed by using statistical package for social science (SPSS) version 20. The binary logistic regression model was fitted to identify factors associated with low vision, and variables with a $P$ value of $<0.05$ in a multivariable binary logistic regression were considered as statistically significant. Results. A total of 715 study participants have participated in this study with a mean age of $49.39 \pm 19.93$ years. The prevalence of low vision was $35.7 \%$ (95\% CI: $32.3,39.3)$. Being female (AOR $=1.58 ; 95 \%$ CI: 1.10, 2.28$)$, no formal educational level $(\mathrm{AOR}=2.24 ; 95 \% \mathrm{CI}: 1.25,4.02)$, history of cataract surgery ( $\mathrm{AOR}=2.58 ; 95 \% \mathrm{CI}: 1.53,4.36)$, and age $\geq 70$ years (AOR: 3.96; 95\% CI: 2.21, 7.10) were significantly associated with low vision. Conclusion and Recommendation. The prevalence of low vision found in this study was high as compared with the national and global magnitude. Older age, being female, previous history of cataract surgery, and no formal education were independently and significantly associated with low vision. Cataract and uncorrected refractive errors were identified as the main causes of low vision. Therefore, it requires a plan to provide an eye care education to the community, increasing the quality of cataract surgery and refractive service for the community in the catchment area.
\end{abstract}

\section{Introduction}

Low vision is defined as a presenting visual acuity (VA) of less than $6 / 18$ but equal to or better than $3 / 60$ in the better eye. It includes both moderate and severe visual impairments [1]. According to the Lancet Global Health Estimate in 2015, about 217 million people had low vision globally, of whom 118.9 and 172.3 million people with low vision were females, and their age was greater than 50 years and above, respectively [2].
On the other hand, a systematic review showed that the prevalence of low vision was $4.0 \%$ in sub-Saharan Africa. It is also reported that the number of people with low vision was varied in the subregion of Africa which ranges from the highest in West Africa (7.2 million) to lowest in Central Africa (1.4 million) [3]. Ethiopia is believed to have one of the world's highest rates of low vision (3.7\%), of which more than $91.2 \%$ are either treatable or preventable causes [4]. Low vision can cause physical, economic, and psychological impact which leads to a reduced quality of life. In another 
way, when a person with low vision is not able to perform job-related functions at the workplace; loss of income and dependency occur [5].

Population-based studies conducted in Asian countries reported that the prevalence of low vision ranges from 3.09\% to $22.1 \%$ [6-12]. On the other hand, institution-based research studies done in Africa showed that the prevalence of low vision extends from $17.1 \%$ to $28.2 \%$ [13, 14].

In Ethiopia, a national survey of low vision and blindness in 2005/6 showed that the prevalence of low vision was 3.7\% and that of blindness was $1.6 \%$ [4]. Besides, a communitybased study in the Gurage Zone, Southern Ethiopia, reported that the prevalence of low vision was $12.1 \%$ [15]. However, a hospital-based study in Addis Abeba, Central Ethiopia, showed that the prevalence of low vision was $10.3 \%$ [16].

Low vision is a priority agenda for Vision 2020, and it is also a public health problem in Ethiopia. As evidenced by outpatient registration, low vision is more common among the adult population attending the University of Gondar tertiary eye care and training center. The main objective of this study was to assess the proportion and associated factors of low vision among the adult population attending the University of Gondar tertiary eye care and training center. Also, this study will provide evidence to plan a way of improving an eye care service for the community in the catchment area of the hospital. Additionally, it helps to facilitate resource mobilization in the eye care system and low vision service.

\section{Method and Materials}

2.1. Study Design, Period, and Area. A hospital-based crosssectional study was employed at the University of Gondar tertiary eye care and training center in Gondar Town from April 18 to May 16, 2019. Gondar Town is located 738 kilometers away from Addis Ababa, the capital city of Ethiopia. The University of Gondar tertiary eye care and training center is the only tertiary eye care center in the Amhara region providing comprehensive eye care service for the Northwest region of the country which comprises a total population of about 5 million. It has senior ophthalmologists, cataract surgeons, optometrists, ophthalmic nurses, and other assistant professionals with advanced ophthalmic equipment. As evidenced by the registration logbook of the center, the University of Gondar tertiary eye care and training center gives different services for about 31,200 patients per year in both outpatient and inpatient departments. It provides medical therapy, surgical services, laser services, and refraction with optical correction. There is also a newly established low vision clinic (since September 2018) in the center that provides low vision examination and low vision aids even though there is a scarcity of aids.

\subsection{Study Population and Eligibility Criteria. The study} participants were patients attending at the University of Gondar tertiary eye care and training center for an eye examination during the time of data collection. All patients, 18 years of age and above, were eligible to participate in the study.
2.3. Ethical Approval. Ethical clearance was obtained from the Institutional Ethical Review Board at the University of Gondar, College of Medicine and Health Sciences, School of Medicine. Oral informed consent was obtained from all participants after explaining the purpose of the study. Participants were informed about their right to withdraw from the study at any time during the interview and examination. The selected study subjects were not receiving any incentive or no risk would be imposed. The privacy and confidentiality of the study participants were secured by avoiding personal identifiers from data collection tools, and the data were locked with a password. The study participants with low vision were immediately linked to particular specialty and refraction clinics.

\subsection{Sample Size Determination and Sampling Procedure.} The sample size was determined based on the assumption that the expected proportion of low vision was $10.3 \%$ taken from a similar study in Addis Ababa [16], with 95\% confidence level and the maximum allowable error of $2 \%$. Then, the sample size was modified for a finite population with a reduction formula as the average number of patients come to the center per month was about 2600 . Finally, $10 \%$ was considered for the nonresponse rate. A systematic random sampling technique with an interval of 4 was employed to select the study subjects. A single number was taken from 1 to 4 with a lottery method to determine the first subject and continue with every 4 intervals. The interval was calculated by dividing the expected number of patients come to the center per month to the total sample size $(N=2600 ; n=727$; $K=(2600 / 727)=4)$.

2.5. Operational Definition. The low vision was defined according to the World Health Organization's revised definition of visual impartment; it included both moderate and severe visual impairment [1].

Moderate visual impairment was defined as a presenting visual acuity of less than $6 / 18$ and better than or equal to $6 / 60$ in the better eye, whereas severe visual impairment was defined as a presenting visual acuity of $<6 / 60$ and better than or equal to $3 / 60$ in the better eye.

The low vision was defined as a presenting visual acuity (VA) of less than $6 / 18$ but better than or equal to $3 / 60$ in the better eye.

2.6. Data Collection Procedures (Personnel and Instrument). Five trained optometrists have participated in data collection. The training was given for data collectors on how to collect the data by the principal investigator. During the data collection, the reliability between raters was checked which gave a kappa score of 0.82 . The data were collected using a structured questionnaire combined with a physical eye examination. The questionnaire includes questions covering the sociodemographic and economic data, behavioral factors, past ocular and medical history. In ophthalmic eye examination, distance visual acuity was measured using the distance Snellen acuity chart with tumbling E optotypes at a 
TABLE 1: Sociodemographic and economic characteristics of study participants, the University of Gondar tertiary eye care and training center, Northwest Ethiopia, $2019(n=715)$.

\begin{tabular}{|c|c|c|}
\hline Variables & Frequency & Percent (\%) \\
\hline \multicolumn{3}{|l|}{ Age (years) } \\
\hline$\leq 40$ & 272 & 38 \\
\hline $40-49$ & 63 & 8.8 \\
\hline $50-59$ & 95 & 13.3 \\
\hline $60-69$ & 123 & 17.2 \\
\hline$\geq 70$ & 162 & 22.7 \\
\hline \multicolumn{3}{|l|}{ Sex } \\
\hline Male & 421 & 58.9 \\
\hline Female & 294 & 41.1 \\
\hline \multicolumn{3}{|l|}{ Residence } \\
\hline Rural & 370 & 51.7 \\
\hline Urban & 345 & 48.3 \\
\hline \multicolumn{3}{|l|}{ Marital status (currently) } \\
\hline Single & 189 & 26.4 \\
\hline Married & 526 & 73.6 \\
\hline \multicolumn{3}{|l|}{ Education } \\
\hline No formal education & 441 & 61.7 \\
\hline Formal education & 274 & 38.3 \\
\hline \multicolumn{3}{|l|}{ Occupation } \\
\hline Farmer & 259 & 36.2 \\
\hline Housewife & 135 & 18.9 \\
\hline Retired & 42 & 5.9 \\
\hline Student & 87 & 12.2 \\
\hline Government employer & 118 & 16.5 \\
\hline Others & 74 & 10.3 \\
\hline \multicolumn{3}{|c|}{ Monthly income (Ethiopian birr) } \\
\hline$\leq 1000$ & 261 & 36.5 \\
\hline $1001-1500$ & 152 & 22 \\
\hline $1501-2500$ & 128 & 17.9 \\
\hline$>2500$ & 169 & 23.6 \\
\hline
\end{tabular}

Education categories, no formal education (can read and write or not) and formal education (primary school (1-8th), high school (8-12th), and college/university (diploma, degree, and above)).

distance of 6 meters in good illumination. Pinhole vision was taken for individuals whose distance visual acuity was less than $6 / 9$ to exclude whether the reduction of visual acuity is due to refractive error or not. If pinhole visual acuity was better than the baseline visual acuity, refractive error was considered as the cause of low vision.

However, a refractive error was considered as the cause of low vision after full eye examination was done to exclude any ocular condition that got improved through a pinhole.

Both anterior and posterior segment eye examination was done to identify ocular conditions that cause low vision. The anterior segment eye examination was done using a slitlamp biomicroscope (SLB). However, the posterior segment (retina and macular) eye examination was performed with the use of 90 Diopter Volk lens and slit-lamp biomicroscope through a dilated pupil.

2.7. Data Quality Assurance. Data quality was controlled by using a pretested structured questionnaire. Training was given to data collectors (optometrists) and supervision was also made by a senior optometrist during data collection. The completeness of the data was checked onsite during the data collection and data entry period by the principal investigator.

2.8. Data Processing and Analysis. The collected data were coded and entered into Epi Info version 7 and then exported to SPSS version 20 for analysis. Descriptive statistics such as frequency distribution and measure of central tendency were used to summarize the descriptive part of the study. Bivariable logistic regression followed by a multivariable binary logistic regression model was fitted to determine the association between dependent and independent variables. The enter method was used to select a significant variable, and the fitness of the model was assessed using the Homer-Lemeshow test. The odds ratio with a 95\% confidence interval was computed to find out the strength of the association between the independent and dependent variables. A variable with a $P$ value of less than 0.05 was considered as statistically significant.

\section{Results}

3.1. Sociodemographic Characteristics of Study Participants. A total of 715 study participants participated in the study with a response rate of $98.6 \%$. The mean age of study participants was $49.39 \pm 19.93$ years (range from 18 to 90 years). Among study participants, 421 (58.9\%) were males and $370(51.7 \%)$ were living in rural areas. Most of the study participants were currently married (562 (73.6\%)). Of the total participants, $441(61.7 \%)$ had no formal education (Table 1).

3.2. Past Ocular, Medical, and Behavioral Characteristics of Study Participants. Among the study participants, 70 (9.79\%) were having a history of cataract surgery and 28 (3.92\%) had a history of hypertension. Out of the total participants, only 36 (5.03\%) of participants used eye-protective sunglasses (Table 2).

3.3. Magnitude of Low Vision. The prevalence of low vision in this study was $35.7 \%$ (95\% CI: $32.3,39.3)$. The main causes of low vision in this study were cataract $(115(44.1 \%))$ and refractive error $(45(17.65 \%))$ (Table 3$)$.

3.4. Factors Associated with Low Vision. By applying bivariable analysis, low vision was positively associated with age, sex, marital status, residence, educational level, occupation, monthly income, and previous history of cataract surgery. However, in a multivariable logistic regression, older age, being female, no formal education, and previous history of cataract surgery were remained significantly associated with low vision. Regarding the educational level of study participants, those who have no formal education were 2.24 times more likely to have low vision than those who have formal education $(\mathrm{AOR}=2.24 ; 95 \% \mathrm{CI}: 1.25,4.02)$.

Participants who had history of cataract surgery were 2.58 times more likely to have low vision as compared with 
TABle 2: Past ocular, medical, and behavioral characteristics of study participants, the University of Gondar tertiary eye care and training center, Northwest Ethiopia, $2019(n=715)$.

\begin{tabular}{|c|c|c|c|c|}
\hline \multirow{2}{*}{ Variables } & \multicolumn{2}{|c|}{ Low vision } & \multirow{2}{*}{ Frequency } & \multirow{2}{*}{ Percent } \\
\hline & Yes & No & & \\
\hline \multicolumn{5}{|c|}{ History of cataract surgery } \\
\hline Yes & 11 & 59 & 70 & 9.79 \\
\hline No & 244 & 401 & 645 & 90.2 \\
\hline \multicolumn{5}{|c|}{ History of any nonsurgical ocular injury } \\
\hline Yes & 23 & 33 & 56 & 7.83 \\
\hline No & 232 & 427 & 639 & 92.17 \\
\hline \multicolumn{5}{|c|}{ History of diabetes mellitus } \\
\hline Yes & 8 & 18 & 26 & 3.64 \\
\hline No & 247 & 442 & 689 & 96.36 \\
\hline \multicolumn{5}{|c|}{ History of hypertension } \\
\hline Yes & 16 & 12 & 28 & 3.92 \\
\hline No & 239 & 448 & 687 & 96.08 \\
\hline \multicolumn{5}{|c|}{ Cigarette smoking } \\
\hline Yes & 5 & 6 & 11 & 1.54 \\
\hline No & 250 & 454 & 704 & 98.45 \\
\hline \multicolumn{5}{|c|}{ Using eye-protective sunglass } \\
\hline Yes & 9 & 27 & 36 & 5.03 \\
\hline No & 246 & 433 & 679 & 94.97 \\
\hline
\end{tabular}

TABle 3: Cause of low vision at the University of Gondar tertiary eye care and training center, Northwest Ethiopia, $2019(n=715)$.

\begin{tabular}{|c|c|c|c|}
\hline \multirow[t]{2}{*}{ Common ocular disorder } & \multirow[t]{2}{*}{ Frequency (\%) } & \multicolumn{2}{|c|}{$\begin{array}{c}\text { Low } \\
\text { vision }\end{array}$} \\
\hline & & Yes & No \\
\hline Cataract & $240(33.57)$ & 115 & 125 \\
\hline Refractive error & $90(12.59)$ & 45 & 45 \\
\hline Glaucoma & $70(9.79)$ & 30 & 40 \\
\hline Corneal opacity & $60(8.39)$ & 25 & 35 \\
\hline Pseudophakia & $70(9.79)$ & 11 & 59 \\
\hline Age-related macular degeneration & $26(3.64)$ & 8 & 18 \\
\hline Diabetic retinopathy & $20(2.80)$ & 6 & 14 \\
\hline Ocular surface diseases & $86(12.02)$ & 5 & 81 \\
\hline Others & $53(7.41)$ & 10 & 43 \\
\hline Total & $715(100 \%)$ & 255 & 460 \\
\hline
\end{tabular}

Others: uveitis, retinal detachment, hypertensive retinopathy, optic neuritis, phthisis bulbi, macular hole, and optic atrophy. Ocular surface diseases: blepharitis, conjunctivitis, and pterygium.

their counter parts $(\mathrm{AOR}=2.58 ; 95 \% \mathrm{CI}: 1.53,4.36)$. In addition, being female was 1.58 times more likely to have low vision than male $(\mathrm{AOR}=1.58 ; 95 \% \mathrm{CI}: 1.10,2.28)$. Study participants whose age greater than or equal to 70 years old were 3.96 times more likely to have low vision as compared with those whose age less than or equal to 40 years old $(\mathrm{AOR}=3.96 ; 95 \% \mathrm{CI}: 2.21,7.10)$ (Table 4).

\section{Discussion}

The burden of low vision in Ethiopia is a public health problem and known to have an impact on socioeconomic value and quality of life in the community. This study was aimed to determine the proportion and associated factors of low vision so that stakeholders will have evidence to plan and implement a strategy for improving an eye care service.
In this study, the prevalence of low vision was $35.7 \%$ (95\% CI: 32.3, 39.3). This result is higher than other previous hospital-based studies done in Addis Abeba, Ethiopia (10.3\%) [16], Ghana (28.2\%) [14], and South Africa (17.1\%) [13]. This difference might result from variation in sampling technique in which the study in South Africa used nonprobability sampling and the data collection techniques, and data source in the Ethiopian and the Ghanian studies were medical records as well as it was done with a large sample size which may contribute for the discrepancy beteween the two studies. Besides, the variation in a socioeconomic characteristic of the study population could also contribute to this difference. On the other hand, the result of this study is higher than studies done in the Gurage Zone of Ethiopia (12.1\%) [15] and a national survey of Ethiopia (3.7\%) [4], Afghanistan (13.9\%) [9], Sri Lankan (19.6\%) [10], Indian states $(9.2-22.1 \%)[8,11,12]$, Malaysia (7\%) [7], and Iran (3.09\%) [6]. This difference might be due to the variation in sampling design and sample size in which those studies were done at the community level with a larger sample size. Additionally, the variation in accessibility and availability of eye care service and socioeconomic status of the study population play a role in this difference $[11,17]$.

In this study, $40.82 \%$ of females had lived with low vision, and being female was 1.58 times more likely to have low vision than males. This finding is in line with studies conducted in the Gurage Zone of Ethiopia [15], Nepal [18], Indian states [17, 19], Saudi Arabia [20], and China [21, 22]. The possible reasons for this variation could be that females have had longer life expectancy than males, which in turn leads to developing eye conditions that could be increasing low vision [23]. Also, this might be happening because females could have unequal access for eye care services in some rural areas and the social stigma of wearing spectacles [18], whereas studies were done in Afghanistan, Sri Lankan, 
TABLE 4: Factors associated with low vision among adult patients attending the University of Gondar tertiary eye care and training center, Northwest Ethiopia, 2019 ( $n=715)$.

\begin{tabular}{|c|c|c|c|c|}
\hline \multirow{2}{*}{ Variables } & \multicolumn{3}{|c|}{ Low vision } & \multirow{2}{*}{$\operatorname{AOR}(95 \% \mathrm{CI})$} \\
\hline & Yes & No & COR $(95 \% \mathrm{CI})$ & \\
\hline \multicolumn{5}{|l|}{ Age (years) } \\
\hline$\leq 40$ & 39 & 233 & 1.00 & 1.00 \\
\hline $40-49$ & 17 & 46 & $2.21(1.15,4.24)$ & $1.35(0.67,2.76)^{*}$ \\
\hline $50-59$ & 41 & 54 & $4.54(2.67,7.70)$ & $2.27(1.22,4.22)^{* * *}$ \\
\hline $60-69$ & 65 & 58 & $6.70(4.10,10.93)$ & $3.25(1.80,5.87)^{* * *}$ \\
\hline$\geq 70$ & 93 & 39 & $8.05(5.08,12.76)$ & $3.96(2.21,7.10)^{* * *}$ \\
\hline \multicolumn{5}{|l|}{ Sex } \\
\hline Male & 135 & 286 & 1.00 & 1.00 \\
\hline Female & 120 & 174 & $1.46(1.07,1.99)$ & $1.58(1.10,2.28)^{* *}$ \\
\hline \multicolumn{5}{|l|}{ Residence } \\
\hline Rural & 167 & 203 & $2.40(1.75,3.30)$ & $0.96(0.64,1.45)$ \\
\hline Urban & 88 & 257 & 1.00 & 1.00 \\
\hline \multicolumn{5}{|l|}{ Marital status (currently) } \\
\hline Single & 42 & 147 & $0.42(0.29,0.62)$ & $0.87(0.54,1.40)$ \\
\hline Married & 213 & 313 & 1.00 & 1.00 \\
\hline \multicolumn{5}{|l|}{ Education } \\
\hline No formal education & 215 & 226 & $5.57(3.79,8.17)$ & $2.24(1.25,4.02)^{* *}$ \\
\hline Formal education & 40 & 234 & 1.00 & 1.00 \\
\hline \multicolumn{5}{|l|}{ Occupation } \\
\hline Farmer & 118 & 141 & $5.34(2.98,9.54)$ & $1.31(0.52,3.30)$ \\
\hline Housewife & 69 & 66 & $6.67(3.57,12.46)$ & $1.81(0.70,4.73)$ \\
\hline Retired & 24 & 18 & $8.50(3.79,19.05)$ & $2.29(0.80,6.52)$ \\
\hline Student & 10 & 17 & $0.83(0.36,193)$ & $1.40(0.50,4.00)$ \\
\hline Others & 18 & 56 & $2.05(0.97,4.33)$ & $1.04(0.43,2.57)$ \\
\hline Government employer & 16 & 102 & 1.00 & 1.00 \\
\hline \multicolumn{5}{|c|}{ Monthly income (Ethiopian birr) } \\
\hline$\leq 1000$ & 106 & 155 & $2.93(1.85,4.63)$ & $0.99(0.55,1.76)$ \\
\hline $1001-1500$ & 65 & 92 & $3.03(1.84,4.99)$ & $0.97(0.53,1.77)$ \\
\hline $1501-2500$ & 52 & 76 & $2.93(1.74,4.94)$ & $1.05(0.57,1.95)$ \\
\hline$>2500$ & 32 & 137 & 1.00 & 1.00 \\
\hline \multicolumn{5}{|l|}{ History of cataract surgery } \\
\hline Yes & 55 & 28 & $4.24(2.61,6.89)$ & $2.58(1.53,4.36)^{* *}$ \\
\hline No & 197 & 429 & 1.00 & 1.00 \\
\hline
\end{tabular}

${ }^{*}$ Nonsignificant, ${ }^{* *} P<0.01$, and ${ }^{* * *} P<0.001$. CI, confidence interval; COR, crude odds ratio; AOR, adjusted odds ratio.

North India, and Iran reported that gender was not associated with low vision [6, 9-11].

Regarding the education level of a study participant, those who have no formal education were 2.24 times more likely to have low vision than those having a formal education. Similar findings were reported from studies conducted in Nepal [18], in different states of India [11, 17, 19], and China [24]. The possible reason is that noneducated individuals had low detailed visual demands to performed daily activities that may not enforce to seek the treatment. Also, poor awareness about the problem as well as service and fear for eye care intervention might be contributed to this finding [25].

Previous history of cataract surgery was found to be another determinant factor where those who had a history of cataract surgery were 2.58 times more likely to have low vision than their counterparts. However, this finding is new and unproven in previous studies and against the fact, for example, having surgery for pure cataract could lead to a better outcome rather than low vision. Despite this, the possible reason could be a failure to detect preexisting eye conditions (such as age-related macular degeneration (ARMD), glaucoma, and diabetic retinopathy). And also, postsurgical complications such as posterior capsule opacification (PCO) and postoperative large uncorrected refractive error could worsen the preexisting vision and lead to low vision $[26,27]$.

Older age was also another important factor in which age above 60 years old was more than 3 times at risk to develop a low vision. This finding is supported by studies done in the Gurage Zone of Ethiopia [15], Nepal [18], Sri Lanka [10], and the state of India $[11,17,19]$. The possible reason might be due to the common causes of low vision such as cataract, glaucoma, and age-related macular degeneration are agerelated eye diseases $[13,14]$. However, the study done in Afghanistan showed that age was not associated with low vision [9]. This difference might be due to a variation in age categorization.

As a limitation of the study, there is a scarcity of hospitalbased studies in Ethiopia and other parts of Africa which 
makes the comparison and discussion of the findings with population-based studies. Additionally, the definition of low vision was made based on the presenting visual acuity which brings difficulty in estimating the proportion of low vision individuals who really need optical low vision aids at the time of the study.

\section{Conclusion}

The prevalence of low vision found in this study was high as compared with the global and national prevalence of low vision. Older age, being female, previous of history cataract surgery, and no formal education were independently and significantly associated with low vision. Cataract and uncorrected refractive errors were the main causes of low vision. Therefore, it requires a plan to provide an eye care education to the community, increasing quality cataract surgery and refractive services. Additionally, researchers shall conduct further studies which clearly shows the need of low vision aids by considering the service provision aspect of low vision.

\section{Data Availability}

All the necessary data are included in the manuscript, and if needed, the supporting data are availed.

\section{Conflicts of Interest}

The authors declare that they have no conflicts of interest.

\section{Acknowledgments}

The authors would like to acknowledge the University of Gondar for financial support. The authors would also like to acknowledge study participants for their participation in the study. Last but not the least, the authors want to express their deepest gratitude for all clinical and academic optometry staff members for their contribution during the data collection and the research process as a whole.

\section{References}

[1] World Health Organization, List of Official ICD-10 Updates Ratified October 2006, WHO, Geneva, Switzerland, 2006, http://www.who.int/classifications/icd/2006Updates.pdf.

[2] R. R. A. Bourne, S. R. Flaxman, T. Braithwaite et al., "Magnitude, temporal trends, and projections of the global prevalence of blindness and distance and near vision impairment: a systematic review and meta-analysis," The Lancet Global Health, vol. 5, no. 9, pp. e888-e897, 2017.

[3] K. Naidoo, S. Gichuhi, M.-G. Basáñez et al., "Prevalence and causes of vision loss in sub-Saharan Africa: 1990-2010," British Journal of Ophthalmology, vol. 98, no. 5, pp. 612-618, 2014.

[4] Y. Berhane, A. Worku, A. Bejiga et al., "Prevalence and causes of blindness and low vision in Ethiopia," Ethiopian Journal of Health Development, vol. 21, no. 3, pp. 204-210, 2007.

[5] R. Omar, "Low vision rehabilitation can improve quality of life," Jurnal Kebajikan Masyarakat (Social Welfare Journal), vol. 36, no. 6, pp. 99-110, 2010.
[6] H. Hashemi, M. Khabazkhoo, M. Saatchi, H. Ostadimoghaddam, and A. Yekta, "Visual impairment and blindness in a populationbased study of Mashhad, Iran," Journal of Current Ophthalmology, vol. 30, no. 2, pp. 161-168, 2018.

[7] F. L. M. Chew, M. A. Salowi, Z. Mustari et al., "Estimates of visual impairment and its causes from the national eye survey in Malaysia (NESII)," PLoS One, vol. 13, no. 6, Article ID e0198799, 2018.

[8] L. Vijaya, R. George, R. Asokan, L. Velumuri, and S. V. Ramesh, "Prevalence and causes of low vision and blindness in an urban population: the Chennai glaucoma study," Indian Journal of Ophthalmology, vol. 62, no. 4, pp. 477-481, 2014

[9] M. H. Abdianwall and B. G. Dogan, "Prevalence of visual impairment and related factors in Nangarhar province of Afghanistan: a cross-sectional study," International Journal of Ophthalmology, vol. 11, no. 12, pp. 1968-1977, 2018.

[10] C. Abeysena and H. Champa, "Prevalence of visual impairment among adults aged forty years and above in a medical officer of health area in Sri Lanka: cross-sectional study," International Archives of Public Health and Community Medicine, vol. 2, no. 1, p. 013, 2018.

[11] S. Malhotra, P. Vashist, M. Kalaivani et al., "Prevalence and causes of visual impairment amongst older adults in a rural area of North India: a cross-sectional study," BMJ Open, vol. 8, no. 3, Article ID e018894, 2018.

[12] C. R. Rao, R. S. Shetty, S. S. Narayanan, S. Kini, V. Kamath, and A. Kamath, "Prevalence of visual impairment in adults aged 18 years and above in a rural area of coastal Karnataka," International Journal of Health \& Allied Sciences, vol. 7, no. 1, pp. 31-36, 2018.

[13] M. M. Maake and O. A. Oduntan, "Prevalence and causes of visual impairment in patients seen at Nkhensani hospital eye clinic, South Africa," African Journal of Primary Health Care \& Family Medicine, vol. 7, no. 1, pp. 1-6, 2015.

[14] D. O. Ansah, "Prevalence and causes of visual impairment among patients in Juaben hospital eye clinic, Ghana," Mathews Journal of Ophthalmology, vol. 2, no. 2, p. 017, 2017.

[15] M. Melese, W. Alemayehu, S. Bayu et al., "Low vision and blindness in adults in Gurage Zone, central Ethiopia," British Journal of Ophthalmology, vol. 87, no. 6, pp. 677-680, 2003.

[16] F. M. Cherinet, S. Y. Tekalign, D. H. Anbesse, and Z. Y. Bizuneh, "Prevalence and associated factors of low vision and blindness among patients attending St. Paul's hospital millennium medical college, Addis Ababa, Ethiopia," BMC Ophthalmology, vol. 18, no. 1, 2018.

[17] S. Marmamula, S. Narsaiah, K. Shekhar, R. C. Khanna, and G. N. Rao, "Visual impairment in the South Indian state of Andhra Pradesh: Andhra Pradesh-rapid assessment of visual impairment (AP-RAVI) project," PLoS One, vol. 8, no. 7, Article ID e70120, 2013.

[18] R. Thapa, S. Bajimaya, G. Paudyal et al., "Prevalence and causes of low vision and blindness in an elderly population in Nepal: the Bhaktapur retina study," BMC Ophthalmology, vol. 18, no. 1, p. 42, 2018.

[19] N. Gupta, P. Vashist, S. Malhotra, S. S. Senjam, V. Misra, and A. Bhardwaj, "Rapid assessment of visual impairment in the urban population of Delhi, India," PLoS One, vol. 10, no. 4, Article ID e0124206, 2015.

[20] F. F. Al-Shaaln, M. A. Bakrman, A. M. Ibrahim, and A. S. Aljoudi, "Prevalence and causes of visual impairment among Saudi adults attending primary health care centers in Northern Saudi Arabia," Annals of Saudi Medicine, vol. 31, no. 5, pp. 473-480, 2011. 
[21] C.-W. Pan, D.-J. Qian, H.-P. Sun, Q. Ma, Y. Xu, and E. Song, "Visual impairment among older adults in a rural community in Eastern China," Journal of Ophthalmology, vol. 2016, p. 6, Article ID 9620542, 2016.

[22] X. Yan, L. Chen, and H. Yan, "Socio-economic status, visual impairment and the mediating role of lifestyles in developed rural areas of China," PLoS One, vol. 14, no. 4, Article ID e0215329, 2019.

[23] C. A. McCarty, B. N. Mukesh, P. N. Dimitrov, and H. R. Taylor, "The incidence and progression of cataract in the melbourne visual impairment project," American Journal of Ophthalmology, vol. 136, no. 1, pp. 10-17, 2003.

[24] C. Guo, Z. Wang, P. He, G. Chen, and X. Zheng, "Prevalence, causes and social factors of visual impairment among Chinese adults: based on a national survey," International Journal of Environmental Research and Public Health, vol. 14, no. 9, p. 1034, 2017.

[25] S. Marmamula, R. C. Khanna, K. Shekhar, and G. N. Rao, "A population-based cross-sectional study of barriers to uptake of eye care services in South India: the rapid assessment of visual impairment (RAVI) project," BMJ Open, vol. 4, no. 6, p. e005125, 2014

[26] O. O. Olawoye, A. O. Ashaye, C. O. Bekibele, and B. G. K. Ajayi, "Visual outcome after cataract surgery at the university college hospital, ibadan," Annals of Ibadan Postgraduate Medicine, vol. 9, no. 1, 2011.

[27] F. K. Hashmi, Q. A. Khan, T. A. Chaudhry, and K. Ahmad, "Visual outcome of cataract surgery," Journal of the College of Physicians and Surgeons Pakistan, vol. 23, no. 6, pp. 448-449, 2013. 